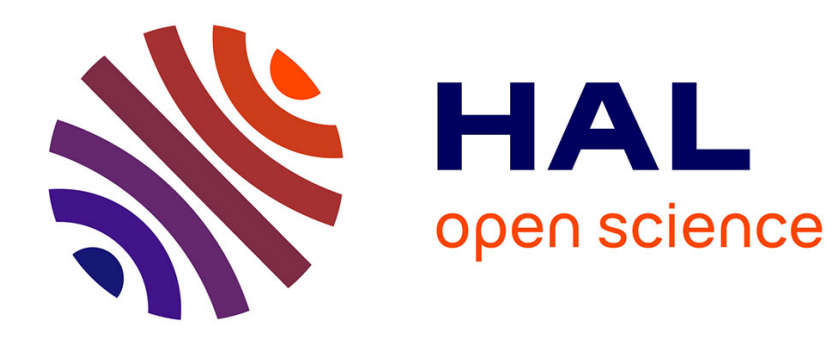

\title{
Dimensionality of subnetworks in amorphous covalent alloys
}

\author{
R. Mosseri, J. Dixmier
}

\section{To cite this version:}

R. Mosseri, J. Dixmier. Dimensionality of subnetworks in amorphous covalent alloys. Journal de Physique Lettres, 1980, 41 (1), pp.5-7. 10.1051/jphyslet:019800041010500 . jpa-00231710

\section{HAL Id: jpa-00231710 https://hal.science/jpa-00231710}

Submitted on 1 Jan 1980

HAL is a multi-disciplinary open access archive for the deposit and dissemination of scientific research documents, whether they are published or not. The documents may come from teaching and research institutions in France or abroad, or from public or private research centers.
L'archive ouverte pluridisciplinaire HAL, est destinée au dépôt et à la diffusion de documents scientifiques de niveau recherche, publiés ou non, émanant des établissements d'enseignement et de recherche français ou étrangers, des laboratoires publics ou privés. 


\title{
Dimensionality of subnetworks in amorphous covalent alloys
}

\author{
R. Mosseri and J. Dixmier \\ Laboratoire de Physique des Solides, CNRS, 1, place A.-Briand, 92190 Meudon, France
}

(Reçu le 28 août 1979, accepté le 15 novembre 1979)

\begin{abstract}
Résumé. - On montre que, dans l'hypothèse du réseau chimiquement ordonné, il existe des relations simples entre connectivité et dimensionnalité des sous-réseaux d'alliages covalents amorphes. L'existence d'une concentration seuil pour la présence d'amas infinis d'atomes de même type est rapidement discutée.
\end{abstract}

\begin{abstract}
We show that, within the chemically ordered network approximation, simple relationships exist between connectivity and dimensionality of subnetwork of amorphous covalent alloys. We then rapidly discuss the existence of a concentration threshold for the presence of infinite cluster of identical atoms.
\end{abstract}

1. Introduction. - In a recent paper Connell and Lucovsky [1] have presented a method for systematically describing local order in amorphous covalent alloys $A_{1-x} B_{x}$. They specify the network structure in four stages : the coordination number at each atomic site, the distribution of different bond types AA, $\mathrm{AB}, \mathrm{BB}$, the symmetry of local molecular environments and the topological rules for the network connectivity. The word connectivity includes concepts such as coordination, diedral angle statistic and ring closure. They focused on two models, the random covalent network (RCN) model and the chemically ordered (CO) model which both satisfy the $8-N$ rule (the coordination on every atomic site equals $8-N$ where $N$ is the number of the column of the periodic table for the considered element). This rule is very often verified for the amorphous solids of column IV, V, VI. One measures experimentally a coordination number close to 4 for amorphous silicon (aSi) and aGe, 3 for aAs and aSb, 2 for aSe and aTe. Binary alloys between the different elements are easy to obtain in the amorphous state within a wide range of compositions. These alloys sometime disobey the 8- $N$ rule in their crystalline phase. This is mainly due to periodicity requirements and hence is not to be expected in the amorphous phase where the longe range constraints disappear.

We propose to use, in addition to the four Connell's arguments, considerations about the dimensionality of bonds between like atoms, i.e. the dimensionality of the like atoms subnetwork. This is possible within the $\mathrm{CO}$ approximation which corresponds to the maximum local order (by repulsion between like atoms when they are first neighbours). This model is a limit approximation (maximum number of $A B$ bonds) which seems to be reasonable for many amorphous covalent alloys. We shall suppose the network to be ideally realized (without dangling bonds) and homogeneous with respect to the spatial repartition of $\mathrm{AB}$ bonds.

2. General case. - Considering an alloy $A_{1-x} B_{x}$ let $z_{\mathrm{A}}\left(z_{\mathrm{B}}\right)$ be the total number of first neighbours of $\mathrm{A}(\mathrm{B})$ as given by the 8- $N$ rule (except for the case of hydrogen in $\mathrm{aSi}_{1-x} \mathrm{H}_{x}$ for which we suppose $z_{\mathrm{H}}=1$ ). We are limited to the case :

$$
z_{\mathrm{A}}<4 ; \quad z_{\mathrm{B}}<4 ; \quad z_{\mathrm{A}} \text { or } z_{\mathrm{B}}>1 .
$$

The CO model includes a critical compound composition $x_{\mathrm{c}}=z_{\mathrm{A}} /\left(z_{\mathrm{A}}+z_{\mathrm{B}}\right)$ for which there are only $\mathrm{AB}$ bonds. The partial coordination numbers (which are mean values averaged over the whole network) are given by :

$$
\left.\begin{array}{l}
C_{\mathrm{AA}}=z_{\mathrm{A}}-z_{\mathrm{B}} \frac{x}{1-x} \\
C_{\mathrm{BB}}=0 \\
C_{\mathrm{AB}}=z_{\mathrm{B}} \frac{x}{1-x} \\
C_{\mathrm{BA}}=z_{\mathrm{B}} \\
C_{\mathrm{AA}}=0 \\
C_{\mathrm{BB}}=z_{\mathrm{B}}-z_{\mathrm{A}} \frac{1-x}{x} \\
C_{\mathrm{AB}}=z_{\mathrm{A}} \\
C_{\mathrm{BA}}=z_{\mathrm{A}} \frac{1-x}{x}
\end{array}\right\} x_{\mathrm{c}}<x<1 . x_{\mathrm{c}}
$$


Let us define the local dimensionality $D_{\mathrm{xx}}$ of a local arrangement of bonds around a given atom of type $X$ by :

$1+D_{\mathrm{XX}}=$ number of $\mathrm{X}$ type first neighbours of the given $\mathrm{X}$ atom .

If the alloy is homogeneous we can suppose that the connectivity is nearly the same everywhere. We then define the extended dimensionality $d_{\mathbf{x x}}$, using the (averaged) coordination numbers $C_{\mathbf{X x}}$ by :

$$
1+d_{\mathrm{xx}}=C_{\mathrm{Xx}} \text {. }
$$

As we shall see, this dimensionality $d_{\mathbf{X x}}$ corresponds, when it takes integer values, to the real dimension of the subnetwork of the homogeneous alloy which follows the ideal $\mathrm{CO}$ model. So, using relations (1) and (2), we have the following relationships for the subnetwork $A$ of $A_{1-x} B_{x}$ :

$$
\begin{aligned}
d_{\mathrm{AA}} & =C_{\mathrm{AA}}-1 \\
\frac{\partial C_{\mathrm{AA}}}{\partial x} & =\frac{-\left[\left(z_{\mathrm{A}}+z_{\mathrm{B}}-1\right)-d_{\mathrm{AA}}\right]^{2}}{z_{\mathrm{B}}} .
\end{aligned}
$$

Relation (2) shows that we can have non integer values of $d_{\mathbf{x x}}$ and that is why we use the word dimensionality instead of dimension. $\partial C_{\mathrm{AA}} / \partial x$ can be understood as the rate of rearrangement of the AA bonds, depending on the dimensionality of the subnetwork $\mathrm{A}$ when $x$ varies.

3. Examples. - a) AlloY $\mathrm{aSi}_{1-x} \mathrm{H}_{x} \quad\left(z_{\mathrm{Si}}=4\right.$, $\left.z_{\mathrm{H}}=1\right)$. - The critical value $x_{\mathrm{c}}$ is 0.8 but, since monovalent $H$ cannot build a subnetwork, we are confined to the range $x<x_{\mathrm{c}}$. We focus on the silicon matrix for which $C_{\mathrm{SiSi}}$, following (1), is given by : $C=4-x /(1-x)$ (Fig. 1). Furthermore it is impos-

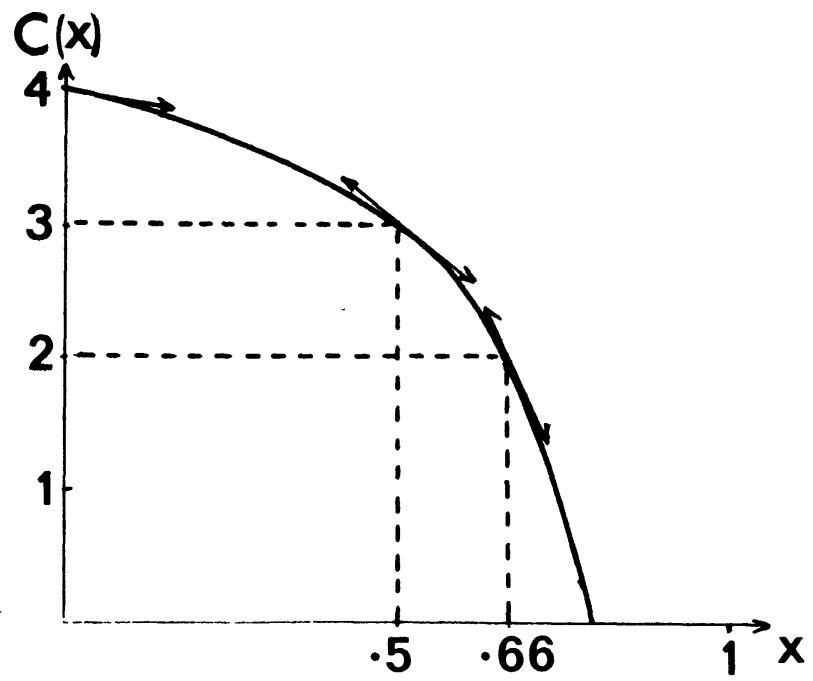

Fig. 1. - Plot of the Si-Si coordination number versus Hydrogen content $x$. The arrows indicate $\partial C / \partial x$ for the three values of $x$ discussed in the text $(x=0,0.5,0.66)$. sible to build an infinite structure for $x>0.66$ so we shall divide the discussion in two parts :

(i) $x<0.66$

$-C=4$ and $x=0$ correspond to the non hydrogenated aSi and therefore to the three dimensional $(3 D)$ random network [2] :

$$
\left.\frac{\partial C}{\partial x}\right|_{x=0}=-1 \text {. }
$$

- $C=3$ and $x=0.5$ correspond to a $2 D$ corrugated layer if $\mathrm{H}$ is completely spread out (no $\mathrm{Si}-\mathrm{H}_{2}$ bonds) :

$$
\left.\frac{\partial C}{\partial x}\right|_{x=0.5}=-4 .
$$

$-C=2$ and $x=0.66$ correspond to the chainlike structure of $\left(\mathrm{SiH}_{2}\right)_{n}$ :

$$
\left.\frac{\partial C}{\partial x}\right|_{x=0.66}=-9 \text {. }
$$

For these three integer values of the coordination number, there is an agreement between the real dimension of the silicon matrix and the dimensionality defined by $d_{\mathrm{SiSi}}=C_{\mathrm{SiSi}}-1$.

The different values of $\partial C / \partial x$ show that, when increasing the $\mathrm{H}$ concentration, there is a greater rearrangement of the Si matrix for a little change of $x$.

(ii) $0.66<x<x_{\mathrm{c}}$

$-x=0.8$ correspond to the molecule $\mathrm{SiH}_{4}$ $\left(C_{\mathrm{SiSi}}=0\right.$ which gives $\left.d=-1\right)$. By decreasing $x$ we next obtain $\mathrm{Si}_{2} \mathrm{H}_{6}$ for $x=0.75(C=1$ and $d=0)$ and so on until $x=0.66$. Thus we have reviewed all the polymers of intermediate dimensionality between 0 and 1.

All these results are summarized table I.

b) Alloy IV-VI (FOR EXAMPLE $\mathrm{aGe}_{1-x} \mathrm{Se}_{x}$ OR $\mathrm{aSi}_{1-x} \mathrm{O}_{x}$ ). $-\mathrm{A}$ belongs to column IV and $x_{\mathrm{c}}=0.66$. Using relations (1) we obtain the following relations for the coordination numbers :

$$
\begin{aligned}
& \left.\begin{array}{l}
C_{\mathrm{AA}}=4-2 \frac{x}{1-x} \\
C_{\mathrm{BB}}=0
\end{array}\right\} 0<x<x_{\mathrm{c}} \\
& \frac{\partial C_{\mathrm{AA}}}{\partial x}=\frac{-\left(5-d_{\mathrm{AA}}\right)^{2}}{2} \\
& \left.\begin{array}{l}
C_{\mathrm{AA}}=0 \\
C_{\mathrm{BB}}=2-4 \frac{1-x}{x}
\end{array}\right\} x_{\mathrm{c}}<x<1 \\
& \frac{\partial C_{\mathrm{BB}}}{\partial x}=\frac{\left(5-d_{\mathrm{BB}}\right)^{2}}{4} .
\end{aligned}
$$

These results are illustrated on figure 2 . 
Table I. - Evolution of the dimensionality of the $\mathrm{Si}$ matrix in $\mathrm{Si}_{1-x} \mathrm{H}_{x}$ when $x$ varies from 0.8 to 0 .

\begin{tabular}{llll}
\multicolumn{1}{c}{$x$} & \multicolumn{1}{c}{ Material } & \multicolumn{1}{c}{$d$} & \multicolumn{1}{c}{$C$} \\
0.8 & - & -1 & 0 \\
0.75 & $\mathrm{SiH}_{4}$ & 0 & 1 \\
0.727 & $\mathrm{Si}_{2} \mathrm{H}_{6}$ & 0.33 & 1.33 \\
0.714 & $\mathrm{Si}_{3} \mathrm{H}_{8}$ & 0.5 & 1.5 \\
0.66 & $\mathrm{Si}_{4} \mathrm{H}_{10}$ & 1 & 2 \\
0.5 & $\left(\mathrm{SiH}_{2}\right)_{n}$ & 2 & 3 \\
0 & $\mathrm{Si}_{0.5} \mathrm{H}_{0.5}$ & & \\
0 & corrugated network & 3 & 4
\end{tabular}

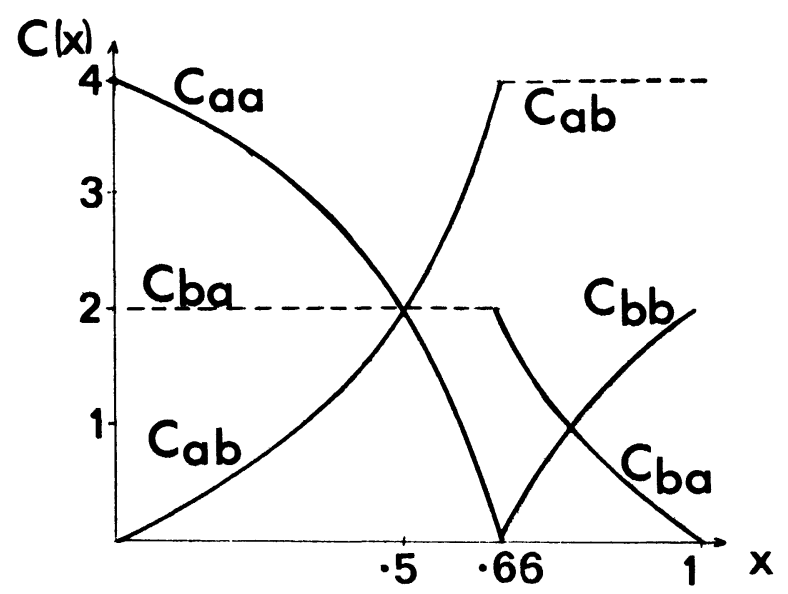

Fig. 2. - Plot of the different partial coordination numbers in the case of the IV-VI alloy : $\mathrm{aGe}_{1-x} \mathrm{Se}_{x}$; $\mathrm{a}$ means $\mathrm{Ge}$ and $\mathrm{b}$ means $\mathrm{Se}$.

4. «Percolation ». - We now study the feasibility of making an infinite self avoiding walk on a subnetwork by jumping from one atom to neighbouring like atoms. It is an unusual percolation problem for two main reasons :

- We have to deal with a mixing of two subnetworks with different connectivities instead of a unique network with constant coordination number at each site.

- The atoms A and B are not randomly distributed : their distribution in space follow the rule maximum number of A-B bonds.

The first reason makes the general problem more difficult to solve but the second one allows an easy determination, within the $\mathrm{CO}$ hypothesis, of the concentration threshold for which these infinite walks appear. The maximum alternance of atoms A and $B$ leads to the most unfavourable case for percolation and these walks will be possible just when the dimensionality of the given subnetwork reaches the value 1 . Below the value $d_{\mathrm{AA}}=1$ the subnetwork $\mathrm{A}$ consist in isolated islands of connected A atoms. These islands look like short chains or sometime tree-like configurations with interrupted branches.

The obtained value of the threshold should be considered as a superior limit for any other structural model. We shall call this value $p_{\mathrm{c}}(\mathrm{X})$ to prevent any confusion with the previous defined $x_{\mathrm{c}}$ which is clearly different : at $p_{\mathrm{c}}(\mathrm{X})$ an infinite self avoiding walk is possible on the $\mathrm{X}$ subnetwork while at $x_{\mathrm{c}}$ every $\mathrm{X}$ atom is surrounded only by $\mathrm{Y}$ atom (and reciprocally) and first neighbour walks are impossible on any subnetwork. In the case of the alloy $\mathrm{A}_{1-x} \mathrm{~B}_{x}$, the value $p_{\mathrm{c}}(\mathrm{A})$ of the threshold is given, using relations (1) and (2), by :

$$
p_{\mathrm{c}}(\mathrm{A})=z_{\mathrm{B}} /\left(z_{\mathrm{A}}+z_{\mathrm{B}}-2\right) .
$$

With our notation $p_{\mathrm{c}}$ is related to $1-x$ for the subnetwork A and to $x$ for the subnetwork B.

Let us look at two examples :

$-\mathrm{aSi}_{1-x} \mathrm{H}_{x}$ relation (3) gives :

$$
p_{\mathrm{c}}(\mathrm{Si})=0.33 \quad(=1-x) .
$$

It corresponds to the infinite disordered chain a $\left(\mathrm{SiH}_{2}\right)_{n}$.

$$
\begin{aligned}
-\mathrm{aSi}_{1-x} \mathrm{O}_{x}: & \\
& p_{\mathrm{c}}(\mathrm{Si})=0.5 .
\end{aligned}
$$

We can expect some properties being modified when the concentration of $\mathrm{Si}$ increases from one side to the other of the value 0.5 . One indeed observes some changes in the optical properties (reflectance and dielectric constant results of Phillip [3]).

5. Conclusion. - These remarks about subnetwork dimensionalities in covalent materials should provide a useful tool for structural modeling considerations as well as for electronic properties investigations. But the restrictive $\mathrm{CO}$ hypothesis must actually reduce its validity since wrong bonds and possible failures of the 8- $N$ rule are certainly present in the real material.

\section{References}

[1] Connel, G. A. N., Lucovsky, G., J. non Cryst. Solids $31 \quad$ [2] Polk, J. non Cryst. Solids 5 (1971) 365. (1978) 123. 